\title{
VARIEDADES DE CANA-DE-AÇÚCAR CULTIVADAS IN VITRO COM DIFERENTES FONTES DE NITROGÊNIO
}

\author{
Virgínia M.T. Sabino Donato ${ }^{1,3 *}$; Arnóbio Gonçalves de Andrade²; Terezinha Rangel Câmara² \\ ${ }^{1} R$. Padre Anchieta, 473/601 Torre - CEP: 50710-430 - Recife, PE. \\ ${ }^{2}$ Depto. de Química - UFRPE, R. D. Manoel de Medeiros s/n. Dois Irmãos - CEP: 52171-030 - Recife, PE. \\ ${ }^{3}$ Bolsista da FACEPE/CNPq - IPA. \\ *e-mail: virginia@ipa.br
}

RESUMO: O objetivo deste trabalho foi avaliar o comportamento de três variedades de cana-de-açúcar cultivadas in vitro em diferentes fontes de nitrogênio. $O$ meio de cultura básico utilizado foi constituído dos sais minerais do MS, com as fontes de nitrogênio modificadas de acordo com o tratamento. Os meios de cultura elaborados foram o $M_{1}$ constituído dos sais $M S$ integral (controle); $M_{2}$ no qual a fonte de nitrogênio do meio $M S$ foi substituída por $4,39 \mathrm{~g} / \mathrm{l}$ de glutamina; $\mathrm{M}_{3} \mathrm{com} \mathrm{KNO}_{3}$ como única fonte de nitrogênio e $\mathrm{M}_{4}$ com $\mathrm{KNO}_{3}$ do $\mathrm{MS}+3,0 \mathrm{~g} / \mathrm{l}$ de glutamina. A estes meios foram submetidas as variedades Co-997 $\left(V_{1}\right)$, SP71-6949 $\left(V_{2}\right)$ e SP70-1143 $\left(V_{3}\right)$, totalizando 12 tratamentos, que foram distribuídos de forma inteiramente casualisada com 5 repetições. A partir da análise estatística, foi possível observar para as variáveis estudadas (número e altura dos brotos), que houve diferença significativa entre as médias das variedades, exceto entre $V_{1}$ e $V_{2}$ e também entre os meios de cultura, exceto entre $M_{2}$ e $M_{4}$. Levandose em consideração a relação entre o número e altura dos brotos, a variedade $\left(V_{2}\right)$ mostrou-se superior em relação as demais quando cultivada no meio $M_{3}$ e no meio $M_{1}$.

Palavras-chave: cana-de-açúcar, micropropagação, glutamina

\section{SUGARCANE VARIETIES CULTIVATED IN VITRO WITH DIFFERENT NITROGEN SOURCES}

ABSTRACT: To verify the behaviour of three sugarcane varieties cultivated in vitro using media with different sources of nitrogen, an experiment was carried out under sterile conditions. Twelve treatments were used, represented by three sugarcane varieties: Co 997 (V1), SP 71-6949 (V2) and SP 70-1143 (V3), and four growth media, differing in the source of $\mathrm{N}$ : integral MS salts (M1-control); $4,3 \mathrm{~g} / \mathrm{L}$ of glutamine as the only source of nitrogen (M2); $\mathrm{KNO}_{3}$ of MS salts as the only source of nitrogen (M3) and $\mathrm{KNO}_{3}$ of $\mathrm{MS}$ salts $+3,0$ $\mathrm{g} / \mathrm{l}$ of glutamine (M4). Five replicates were used in a completely randomized design. Based on the variables studied (shoot height and number), significant differences existed among the varieties, except for V1 and V2. There were also differences on growth media, except for M2 and M4. With respect to the shoot numberl height ratio, the variety (V2) was superior when grown in media M1 and M3.

Key words: sugarcane, micropropagation, glutamine, nitrogen source

\section{INTRODUÇÃO}

A cultura da cana-de-açúcar no Brasil é importante tanto no aspecto social como no econômico, pois da sua industrialização são obtidos além do açúcar, o álcool, sendo o açúcar um dos principais produtos brasileiros. As técnicas da cultura de tecidos vêm sendo aplicadas à micropropagação in vitro de cana-deaçúcar, procurando reduzir o tempo necessário para a produção de mudas de boa qualidade e livres de doenças (Lee, 1984).
O meio de cultura descrito por Murashige \& Skoog (1962) é amplamente utilizado para a maioria das culturas. $O$ elemento chave deste meio nutritivo é a presença de altos níveis de nitrogênio na forma de nitrato de amônio, que tem se mostrado benéfico para indução de organogênese in vitro (Ammirato,1983).

O nitrato como única fonte de nitrogênio, é responsável por uma taxa de crescimento razoável para algumas culturas, como a cenoura (Reinert et al. 1967). No entanto, há espécies como o arroz, que não crescem bem na presença 
apenas do nitrato como fonte de nitrogênio (Yatazawa \& Furuhashi, 1968).

Quando o nitrogênio é fornecido somente na forma de sais inorgânicos de amônio, as células in vitro apresentam sintomas de toxidez (Gamborg, 1970; Gamborg \& Shyluk 1970). No entanto, a combinação das duas formas de nitrogênio, amônio e nitrato, estimula - crescimento de muitas espécies in vitro (Sargent \& King 1974). Por outro lado, além do efeito estimulatório do amônio sobre o crescimento, foi observada também uma dependência desta forma de nitrogênio para a embriogênese somática em cenoura (Halperin \& Wetherell, 1965).

Formas orgânicas de nitrogênio, como a caseína hidrolizada, podem ser usadas em cultura de tecidos. A glutamina (precussora dos demais aminoácidos), também tem sido utilizada com muito sucesso na complementação das fontes inorgânicas de nitrogênio, ou ainda como fonte única de nitrogênio, promovendo o crescimento de tecidos in vitro (Caldas et al., 1990).

O nitrogênio é o quarto elemento mais abundante na planta, depois do carbono, hidrogênio e oxigênio. É um constituinte de aminoácidos, nucleotídeos e coenzimas, portanto existe alguma relação entre o teor de nitrogênio e o crescimento das plantas, considerando que um dos principais sintomas da deficiência do nitrogênio é o amarelecimento ou clorose das folhas, devido a inibição da síntese de clorofila (Epstein, 1975), o que resulta, principalmente, na diminuição da fotossíntese e consequentemente, na síntese de aminoácidos essenciais.

É essencial para a micropropagação, tanto da cana-de-açúcar como de outras culturas, que o meio nutritivo elaborado forneça condições para que haja um bom crescimento vegetativo, além de um índice de multiplicação adequada. Sabendo-se que o nitrogênio é um dos responsáveis pelas características desejáveis, descritas acima, foi proposto a realização de um experimento, utilizando diferentes fontes de nitrogênio, a fim de avaliar os seus efeitos sobre o desenvolvimento de variedades de cana-deaçúcar e eficiência para a multiplicação in vitro desta cultura.

\section{MATERIAL E MÉTODOS}

O material vegetal utilizado neste trabalho foi fornecido pelo Laboratório de Cultura de Tecidos da Empresa Pernambucana de
Pesquisa Agropecuária - IPA. Foram utilizados brotos provenientes de plantas cultivadas in vitro. Sob condições assépticas, as plantas foram multiplicadas, uniformemente, em grupos de dois brotos e em seguida inoculadas nos diferentes tratamentos previamente estabelecidos.

O meio de cultura básico utilizado foi o MS, constituído dos sais minerais descritos por Murashige \& Skoog (1962), modificando-se as fontes de nitrogênio de acordo com o tratamento, sendo a concentração final de nitrogênio a mesma para todos. O meio foi acrescido com tiamina (1 $\mathrm{mg} / \mathrm{L})$, inositol $(0,1 \mathrm{~g} / \mathrm{L})$, PVP $(0,1 \mathrm{~g} / \mathrm{L})$, e com os reguladores de crescimento KIN $(0,1 \mathrm{mg} / \mathrm{L})$ e BAP $(0,2 \mathrm{mg} / \mathrm{L})$, e $20 \mathrm{~g} / \mathrm{L}$ de sacarose.

Foram estabelecidos quatro diferentes tratamentos, que consistiram de: Meio $M_{1}$ constituído pelos sais "MS" integral (controle); o meio $M_{2}$, para o qual foram substituídas as fontes de nitrogênio dos sais "MS" por glutamina $(4,39 \mathrm{~g} / \mathrm{L}) ; \circ \mathrm{M}_{3}$ para o qual foi utilizado apenas 0 $\mathrm{KNO}_{3}$ como fonte de nitrogênio e, finalmente o meio $\mathrm{M}_{4}$, constituído de $\mathrm{KNO}_{3}$ do $\mathrm{MS}$ + glutamina $(3,0 \mathrm{~g} / \mathrm{L})$. A estes meios de cultura foram submetidas três variedades de cana-de-açúcar, a Co-997 (V1), SP71-6949 (V2) e SP70-1143 (V3). O experimento constou de um arranjo fatorial $4 \times 3$ (meios de cultura $\times$ variedades), totalizando 12 tratamentos, inteiramente casualisados, com 5 repetições. O experimento foi mantido por 15 dias em sala de crescimento com temperatura e fotoperíodo controlados.

As avaliações foram realizadas 15 dias após a inoculação, levando-se em consideração o número e altura dos brotos, além do percentual de nitrogênio para cada tratamento, para o qual foi utilizada a planta inteira. A concentração de $\mathrm{N}$ foi quantificada pelo método Micro - Kjedhal, segundo as normas regimentadas pela Association of Official Agricultural Chemists, 1975.

\section{RESULTADOS E DISCUSSÃO}

A importância do nitrogênio para o crescimento e morfogênese de tecidos cultivados in vitro tem sido bem estabelecido. A disponibilidade e a forma química do nitrogênio no meio de cultura é de extrema importância. Segundo Caldas et al. (1990), o nitrogênio, na forma de nitrato, é considerado a principal fonte de nitrogênio para o cultivo in vitro. No entanto, há espécies como o arroz, que não crescem bem na presença do nitrato. 
Neste trabalho, observou-se que para a cana-de-açúcar, a presença dos dois íons nitrato e amônio como fonte de nitrogênio $\left(M_{1}\right)$, foi mais favorável tanto para a formação como para o crescimento dos brotos. No entanto, de acordo com os resultados obtidos, observou-se que o nitrato $\left(\mathrm{M}_{3}\right)$ pode ser utilizado, como única fonte de nitrogênio, sem prejuízo para o índice de multiplicação, principalmente, para as variedades Co-997 $\left(\mathrm{V}_{1}\right)$ e SP70-1143 $\left(\mathrm{V}_{3}\right)$, considerando que segundo a análise estatística, o parâmetro número de broto, não mostrou diferença significativa entre os meios $M_{1}$ e $M_{3}$ (TABELA 1). Para o parâmetro altura dos brotos, não foi observado interação significativa entre as variedades e os meios de cultura.

A utilização do nitrato pelas células depende da atividade da enzima redutase do nitrato, que reduz o nitrato a nitrito, composto que em seguida se reduz a amônia. Segundo Giles \& Vasil (1980), a redutase do nitrato mostra atividade in vitro. Neste trabalho as plantas cultivadas nos tratamentos $M_{3} V_{1}, M_{3} V_{2}$ e $M_{3} V_{3}$, não apresentaram amarelecimento, o que pode estar relacionado à atividade da enzima redutase do nitrato.

Observou-se neste trabalho que, para a cana-de-açúcar, a glutamina combinada com nitrato $\left(\mathrm{M}_{2}\right)$ ou sozinha $\left(\mathrm{M}_{4}\right)$ inibiu 0 desenvolvimento dos brotos. No entanto, para a cultura de protoplastos de Cichorium intybus foi a melhor fonte de nitrogênio (Crepy et al., 1982).

$A$ inibição à multiplicação in vitro da canade-açúcar não foi ocasionada por carência de nitrogênio, pois as concentrações de $\mathrm{N}$ reduzido (determinado pelo método Kjeldhal) foram semelhantes as apresentadas pelas plantas que foram cultivadas nos demais meios (TABELA 2). Estes resultados podem ser atribuídos a inabilidade da glutamina em substituir o amônio ou ainda pela sua capacidade em inibir reações metabólicas na célula (Gamborg, 1970).

Por outro lado, segundo Caldas et al. (1998), a glutamina tem sido utilizada com muito sucesso na complementação da fontes inorgânicas de nitrogênio, ou como fonte única deste elemento, estimulando o crescimento de tecidos diversos in vitro.

Pelas características observadas neste trabalho, para os brotos regenerados, principalmente, no meio $\mathrm{M}_{4}$ constataram-se as afirmativas de Gamborg (1970), considerando que as plantas aparentemente absorveram o nitrogênio, mas este não foi metabolizado, pois os brotos não se desenvolveram. A partir da análise química das plantas cultivadas no referido meio, verificou-se que estas apresentaram maior percentual deste elemento, em relação aos demais tratamentos (TABELA 2).

TABELA 1 - Número médio de brotos em função da variedade e do meio de cultura aos 15 dias de cultivo in vitro.

\begin{tabular}{lccc}
\hline \multirow{2}{*}{ Meios de cultura } & \multicolumn{3}{c}{ Variedades } \\
\cline { 2 - 4 } & Co-997 & SP71-6949 & SP70-1143 \\
\hline M1 ("MS"integral) & 4,8 a B & 10,6 a A & 13,6 a A \\
M2 (Glutamina) & 2,8 a A & $0,6 \mathrm{c} \mathrm{A}$ & $0,2 \mathrm{~b} \mathrm{~A}$ \\
M3 (Nitrato) & 4,4 a B & $6,0 \mathrm{~b} \mathrm{~B}$ & 11,4 a A \\
M4 (Nitrato + glutamina) & 4,0 a A & $0,0 \mathrm{c} \mathrm{B}$ & $0,0 \mathrm{~b} \mathrm{~B}$ \\
\hline
\end{tabular}

*Médias sequidas da mesma letra, dentro da mesma coluna ou linha, não diferem entre si pelo teste de Tukey a $5 \%$.

TABELA 2 -Teor de nitrogênio total na planta inteira de cana-de-açúcar,após 15 dias de cultivo in vitro, em meios de cultura com diferentes fontes de $\mathrm{N}$.

\begin{tabular}{llccc}
\hline \multirow{2}{*}{ Meios de cultura } & \multicolumn{4}{c}{ Variedades } \\
\cline { 2 - 4 } & Co-997 & SP71-6949 & SP70-1143 & Média \\
\cline { 2 - 3 } & \multicolumn{4}{c}{ g.kg ${ }^{-1}$} \\
\cline { 2 - 4 } M1 ("MS"integral) & 42,1 & 44,3 & 39,3 & 41,9 \\
M2 (Glutamina) & 40 & 37,1 & 39,3 & 38,8 \\
M3 (Nitrato) & 26,4 & 27,1 & 28,6 & 27,4 \\
M4 (Nitrato+glutamina) & 47,1 & 45 & 47,1 & 46,4 \\
\hline Média & 38,9 & 38,4 & 38,6 & 38,6 \\
\hline
\end{tabular}




\section{CONCLUSÕES}

- A glutamina não é adequada para substituir a fonte reduzida de nitrogênio, no caso o nitrato de amônio.

- O nitrato, aparentemente, pode ser utilizado como única fonte de nitrogênio, dependendo da variedade utilizada em cultivo.

- A glutamina não pode ser utilizada como fonte única de nitrogênio para a cana-deaçúcar.

- A combinação entre o nitrato de potássio e o nitrato de amônio (sais "MS" integral) foi a mais adequada para a micropropagação da cana-de-açúcar.

\section{REFERÊNCIAS BIBLIOGRÁFICAS}

AMMIRATO, P.V. Embriogenesis. In: EVANS, D.A.; SHARP, W.R.; AMMIRATO, P.V. (Ed.) Handbook of plant cell culture. New York: Macmillan, 1983. p.82-123.

CALDAS, L.S.; HARIDASON, P.; FERREIRA, M.E. Meios nutritivos. In: TORRES, A.C.; CALDAS, L.S. (Ed.) Técnicas e aplicações da cultura de tecidos de plantas. Brasília: ABCTP/EMBRAPACNPH, 1990. 443p.

CALDAS, L.S.; HARIDASON, P.; FERREIRA, M.E. Meios nutritivos. In: TORRES, A.C.; CALDAS, L.S.; BUSO, J.A.(Ed.) Cultura de tecidos e transformação genética de plantas. Brasília: EMBRAPA-SPI/ EMBRAPA-CNPH, 1998. p.87-132.

CREPY, L.; CHUPEAU, M.C.; CHUPEAU, Y. The isolation and culture of leaf protoplasts of Cichorium intybus and their regeneration into plants. Zeitschrift fuer Pflanzenphysiologie, v.107, p.123-131, 1982.

EPSTEIN, E. Nutrição mineral de plantas; princípios e perspectivas. Rio de Janeiro: Livros Técnicos e Científicos, 1975. 341p.
GAMBORG, O.L; SHYLUK, J.P. The culture of plant cells with ammonium salts as the sole nitrogen source. Plant Physiology, v.45, p.598-600, 1970.

GAMBORG, O L. The effects of amino acids and ammonium on the growth of plant cells in suspension culture. Plant Physiology, v.45, p.372-375, 1970.

GILES, K.L.; VASIL, I.K. Nitrogen fixation and plant tissue culture. In: VASIL, I.K. (Ed.) Perspectives in plant cell and tissue culture. New York: Academic Press, 1980. p.81-97.

HALPERIN, W; WETHERELL, D.F. Ammonium requirement for embryogenesis in vitro. Nature, v.205, p.519-520, 1965.

ASSOCIATION OF OFFICIAL ANALYTICAL CHEMISTS Official methods of analysis of the official analytical chemists. 12.ed. Washington: AOAC, 1975. 1094p.

LEE, T.S.G. Micropropagação de cana-de-açúcar através de cultura de meristema apical. Saccharum APC, v.7 p.36-39, 1984.

MURASHIGE, T; SKOOG, F.A. Revised medium for rapid growth and bioassays with tabacco tissue cultures. Physiology Plantarum, v.15, p.473-497, 1962.

REINERT, J.; TOZAWA, M; SEMEROFF, S. Nitrogen compounds as factors of embryogenesis in vitro. Nature, v.216, p.1215-1216, 1967.

SARGENT, P.A; KING, J. Investigations of growthpromoting factors in conditioned soybean root cells and in the liquid medium in which they grow: ammonium, glutamine, and amino acids. Canadian Journal of Botany, v.52, p.1747-1755, 1974.

YATAZAWA, M.; FURUHASHI, K. Nitrogen souces for the growth of rice callus tissue. Soil Science and Plant Nutrition, v.14, p.73-79, 1968.

Recebido para publicação em 11.11.98

Aceito para publicação em 13.09.99 